\title{
Comparative Study of the Quality of Adaptation and Satisfaction with Life of Retirees According to Retiring Age
}

\author{
Catherine Hervé*, Nathalie Bailly, Michèle Joulain, Daniel Alaphilippe \\ Psychologie des Ages de la Vie, Université F. Rabelais, \\ Tours, France \\ Email: " catherine.herve@univ-tours.fr
}

Received January $19^{\text {th }}$, 2012; revised February $14^{\text {th }}$, 2012; accepted March $17^{\text {th }}, 2012$

\begin{abstract}
The aim of this study was to compare the quality of adaptation and the satisfaction with life of two groups of adults who retired at different ages. Participants were 579 French retirees: 234 had retired before the age of 60 , and 345 after 60 . The two samples differed in their own perception and appreciation of the age at which they retired.
\end{abstract}

Keywords: Age; Retirement; Transition; Adaptation; Satisfaction; Well-Being

\section{Introduction}

The age of retirement is currently an issue of public concern. Never before have the social and economical costs of retirement given rise to so much debate. Advances in medical care, together with changes in lifestyle and working conditions have considerably increased the lifespan of people in the industrial world. As the population ages, the possibility of retiring early in life has become common practice (Ginn \& Arber, 1996). France has been particularly concerned by demographic change and has carried out many political, economic and social reforms, with the aim of increasing the quality of life of its retirees. A wide range of pension schemes have been developed, facilitateing the decision of when to retire. For example, in the 1980s, to facilitate the transition towards retirement, the French government introduced two bills to improve the financial conditions of older working adults. In the last twenty years, the conditions for taking early retirement have been modified in their content as well as in their goals, and early retirement remains a popular option.

Currently, the majority of research projects in psychology dealing with retirement focus on the factors accounting for the heterogeneity of behaviour during retirement, without considering the impact of age and maturity/preparedness on how retirees adapt during the transition period. Researchers are generally more interested in identifying the factors which may play a role when deciding when to retire (Feldman, 1994, Henkens, 1999), or in analyzing the decision-making process itself (Schulz, Morton, \& Weckerle, 1998). The age factor is nevertheless critical.

Retirement remains one of the most important transition periods in personal and family life. It represents a social and an emotional challenge (Lo \& Brown, 1999). For some, retirement can be an opportunity to set new goals, to start new activities, and can lead to greater life satisfaction (Calasanti, 1996; Maule, Cliff, \& Taylor, 1996). For others, it entails difficulties of adaptation, feelings of distress, and rapid deterioration of physical and psychological health (Bosse, Aldwin, Levenson, \& Work-

\footnotetext{
*Corresponding author.
}

man-Daniels, 1990). Although the event itself is inevitable, people apprehend, anticipate and perceive it differently. The meaning of retirement, its impact on life satisfaction, and successful adaptation differ considerably from one individual to another. We hypothesize that the age at which people stop work influences the way they adapt to retirement.

This study aimed to improve our understanding of the impact of age on how people adapt to retirement, irrespective of the political reforms affecting their social and economic situation. More specifically, we analyzed how retirees perceived their retiring, and the impact this had on their quality of adaptation and satisfaction with life. While some authors have established a positive link between retirement and life satisfaction (Midanik, Soghikian, Ransom, \& Tekawa, 1995), others have suggested that the feeling of well-being decreases in retirement (Elwell \& Maltbie-Crannel, 1981). Other studies have found that retirement is seen as a common event with no notable effect on well-being ("the satisfaction with life is stable" Stull, 1988).

The aim of the present study was to examine further these hypotheses. It compared the quality of adaptation and satisfaction with life of two groups of adults retiring before and after the age of 60 . We investigated whether the two groups shared a similar quality of adaptation and satisfaction with life, and whether they showed similar feelings about the age at which they retired.

\section{Method}

\section{Participants}

The sample consisted of 579 retirees living throughout France. They were divided into two groups: 234 participants had retired before the age of 60 , and 345 had retired at or after 60 . The sample included 276 men (47.26\%) and 303 women (51.88\%), with an average age of 72.2 years (SD 5.6). Their average age of retirement was 58.71 years (SD 5.76). Approximately 58\% of the subjects were married or living with a partner, and approximately $26 \%$ were widowed or single. The majority of participants lived at home (98.97\%). A specific feature of the 
participants concerned their education level which was significantly higher than that of the French population in general. There was a high proportion of graduates, with $39.21 \%$ of the participants having attended university; only $0.5 \%$ did not have any diploma. The characteristics of the sample are shown in Table 1.

\section{Material}

In this comparative study, we investigated various indicators allowing a precise evaluation of the impact of the retiring age on the feeling of well-being and satisfaction at the time of retirement and in the following years. The quality of adaptation to retired life was evaluated through questionnaires about wellbeing (Diener, Such, Lucas, \& Smith, 1999) and satisfaction with life (Ryff \& Keyes, 1995), and the French adaptation of the Boredom Proneness scale (Gana \& Akremi, 1998). It was completed by a list of 26 items taken from the OARS methodology concerning pathologies to which older people are potentially at risk (Duke University, 1978). In addition, two simple items measured the satisfaction of each person with the retiring condition. The first concerned the time of retirement (early, normal or late) and the second measured the retiree's satisfaction with his/her age at retirement ("I would have preferred to retire earlier/at the same age/later"). To summarize, the questionnaire consisted of four scales and two supplementary items (see Table 2).

\section{Procedure}

The participants were all volunteers belonging to the same

Table 1.

Characteristics of the two groups of retirees.

\begin{tabular}{|c|c|c|c|}
\hline & & \multicolumn{2}{|c|}{ Participants who retired } \\
\hline & & $\begin{array}{c}\text { before the age } \\
\text { of } 60 \text { years }\end{array}$ & $\begin{array}{c}\text { at or after } \\
60 \text { years }\end{array}$ \\
\hline \multirow{2}{*}{$\begin{array}{c}\text { Age at } \\
\text { retirement }\end{array}$} & Mean & 54.44 & 61.70 \\
\hline & $S D$ & 5.87 & 2.67 \\
\hline \multirow{2}{*}{ Age } & Mean age & 71.38 & 72.76 \\
\hline & $S D$ & 4.62 & 6.12 \\
\hline \multirow{2}{*}{ Gender (\%) } & Male & 20.55 & 27.12 \\
\hline & Female & 19.86 & 32.47 \\
\hline \multirow{5}{*}{$\begin{array}{c}\text { Family } \\
\text { situation(\%) }\end{array}$} & Married & 25.61 & 33.04 \\
\hline & Widowed & 9.17 & 17.13 \\
\hline & Single & 1.73 & 2.60 \\
\hline & Separated & 3.11 & 6.06 \\
\hline & Unmarried & 0.87 & 0.69 \\
\hline \multirow{3}{*}{$\begin{array}{l}\text { Education } \\
\text { level (\%) }\end{array}$} & No qualifications & 0.35 & 0.18 \\
\hline & Baccalauréat & 18.76 & 31.68 \\
\hline & University & & \\
\hline \multirow{2}{*}{$\begin{array}{c}\text { Place of } \\
\text { residence (\%) }\end{array}$} & Retirement home & 0.34 & 0.69 \\
\hline & Own home & 39.89 & 58.88 \\
\hline
\end{tabular}

Table 2.

Results of the two simple items (satisfaction with the retiring condition).

\begin{tabular}{cccc}
\hline & & \multicolumn{2}{c}{ Participants who retired } \\
\hline & before the & $\begin{array}{c}\text { at or } \\
\text { age of 60 } \\
\text { after 60 }\end{array}$ \\
\hline $\begin{array}{c}\text { Time of } \\
\text { retirement (\%) }\end{array}$ & 1 = Late & 0.35 & 2.26 \\
Mean & 3 = Norly & 29.22 & 12.70 \\
& I would have & 10.61 & 44.87 \\
& preferred to & $\mathbf{2 . 2 5}$ & $\mathbf{2 . 7 1 ^ { * }}$ \\
$\begin{array}{c}\text { Satisfaction } \\
\text { with age at } \\
\text { retirement (\%) }\end{array}$ & 1 = retire earlier & 2.79 & \\
Mean Score & 3 the same age & 23.39 & 4.33 \\
\hline
\end{tabular}

Note: $p<0.00002$.

management pension scheme. They were recruited via an advertisement in a specialized journal which presented the aims of our study and included an application form for people wishing to participate in the project. More than a thousand people returned the form and were sent a questionnaire by e-mail. Eighty-six percent of the questionnaires were returned.

\section{Results}

Average scores were calculated for each adjusted scale and for each simple item in the two groups: those who retired before and after 60 . Analyses of variance were then carried out.

\section{Evaluation of the Retirees' Sense of Satisfaction with Their own Transition to Retirement}

Table 2 shows the results for the two simple items and indicates differences between the two groups in how they evaluated their age at retirement. Participants who retired before the age of 60 described their retirement age as early, and those who retired after 60 said that they retired at the normal time [F (1, $573)=114.39, p<0.00000]$. Adults who retired before the age of 60 would have preferred to retire later in life, whereas those who retired after 60 were satisfied with their age at the time of retiring $[\mathrm{F}(1,571)=18.37, p<0.00002]$.

Additional statistical analyses of the socio-demographic variables revealed little significant effect in this section of the questionnaire. Only marital status had an impact on the younger retirees' characterization of their retirement age: those who were separated considered more than the others that their age at retirement was early $[\mathrm{F}(4,564)=3.42, p<0.008]$.

After analysing the two groups separately, further statistical analyses of the whole group were performed which showed a significant effect of socio-demographic variables. There was a significant effect of gender on how the time of retirement was perceived and satisfaction with age at retirement.

For example, men tended to describe their retirement as early, whereas women generally described theirs as normal $[\mathrm{F}(1,573)$ $=4.4999, p<0.03]$. Men would also have preferred to retire later, whereas most women were satisfied with their age at retirement $[F(1,571)=10.06, p<0.001]$. The level of educa- 
tion also influenced satisfaction with the age of retirement. The participants who had been to university $(\mathrm{M}=2.28)$ would have preferred to retire later in life $[\mathrm{F}(5,553)=5.87, p<0.00002]$. This was also the case for people living together as husband and wife $(\mathrm{M}=2.66)[\mathrm{F}(4,567)=2.51, p<0.04)$.

\section{Quality of Adaptation to Retirement Related to the Age of Leaving Work}

\section{1) Evaluation of well-being}

Well-being was measured by four items with scores varying from 4 to 18 points. Well-being expressed by the whole population was very high $(\mathrm{M}=12.61 ; \mathrm{SD}=1.84)$. No significant difference in the evaluation of well-being was observed between the two sub-groups.

A more detailed analysis of each of the four items was carried out. The results are shown in Figure 1. The items are presented on the $\mathrm{x}$-axis, the average scores on the $\mathrm{y}$-axis. Retirees in both sub-groups were satisfied with the way they managed their time and their financial situation (average scores above 3 on a scale of 4 points). Participants in both groups described their health as relatively satisfactory (around 3.5/5), and similar to what it had been 3 years previously (around 75\%). Nonetheless, individuals who had retired after 60 more readily described their health to be "much better" than that of their peers $[\mathrm{F}(1,572)=4.47, p<0.3]$.

Further statistical analyses were performed to measure the impact of socio-demographic variables on well-being. No significant effect of these variables was observed on the scale of well-being or on any of the four separate items.

2) Satisfaction with life

Satisfaction with life was high in both groups. It was measured on a scale of 2 to 35 points with an average of 25.67 points (SD 5.12). This average was identical for the two groups ( $M=$ 25.28 for all the individuals who had retired before the age of 60 and $M=25.94$ for those who had retired after 60). However, the family situation affected life satisfaction in both groups, married people who had retired before the age of 60 showing greater life satisfaction than other participants $[F(4,560)=$ 4.22, $p<0.002]$.

3) Boredom

Boredom was measured with 28 items, with scores varying from 0 to 22 points. Overall, participants demonstrated very low levels of boredom, with an average score of 6.87 (SD 3.70). There were significant differences according to age at retirement, with participants who had retired before the age of 60 appearing more bored $(\mathrm{M}=7.34)$ than those who retired later $(\mathrm{M}=6.55)[\mathrm{F}(1,531)=5.84, p=0.01]$. No significant effect of socio-demographic variables on boredom was observed.

4) Health

There were 26 items measuring health, and the participants as a whole showed very satisfactory health, with scores varying from 0 to 10 points. The average rate of sickness for the population as a whole was 2.09 (SD 1.62); $13 \%$ claimed to have no illness $(n=72)$, and $6.6 \%(n=39)$ declared that they suffered from five or more pathologies.

Figure 2 shows the number of pathologies experienced by each group of participants since their retirement. The number of pathologies is displayed on the x-axis and the number of people on the $y$-axis. It can be seen that the age of retirement corresponds to significant differences in the health of participants ([F $(1,572)=5.80, p=0.01])$, participants who retired before 60 experiencing more pathologies $(M=2.29)$ than those who retired after $60(\mathrm{M}=1.96)$. Of the participants who retired before $60,9.87 \%$ claimed to have no pathology, whereas $15.74 \%$ of those who retired after 60 described themselves as free of any illness. Similarly, the number of participants who had contracted five or more pathologies since retiring was higher in the group of participants who retired before 60 (8.97\%) than among those who retired after 60 (5.26\%).

No effect of the socio-demographic variables on health was observed in either group.

\section{Factors Determining Satisfaction with the Age of Retirement}

A principal components analysis with varimax rotation was first performed for the whole sample on the four scales expressing the quality of adaptation to retired life. Two factors were identified: 1 ) adaptation related to the former occupation, and 2) adaptation related to health (Table 3).

The first factor explains $38.9 \%$ of the total variance. It is positively linked to satisfaction with life and negatively linked to boredom, suggesting a link between former occupation and adaptation to retirement. The second factor explains $30.9 \%$ of the total variation. It is positively linked to the number of pathologies and refers to the effect of physical capacities on adaptation to retirement.

To identify the factors accounting for satisfaction with the age of retirement and their respective weights, two multiple regression analyses were carried out. A forward stepwise regression analysis was performed for each group in order to

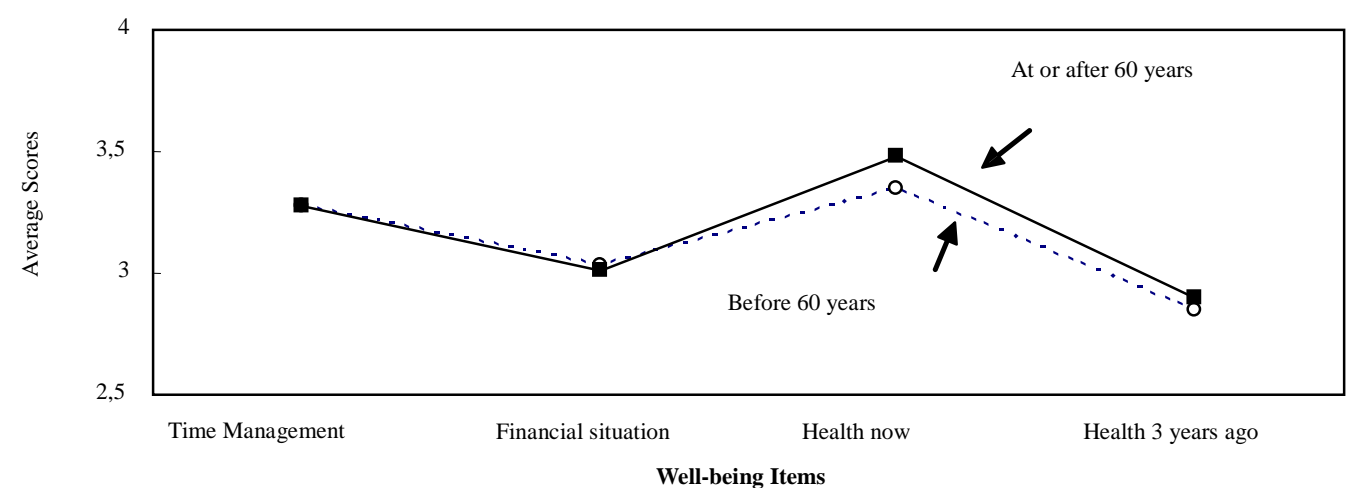

Figure 1.

Results for the four well-being items in the questionnaire. 


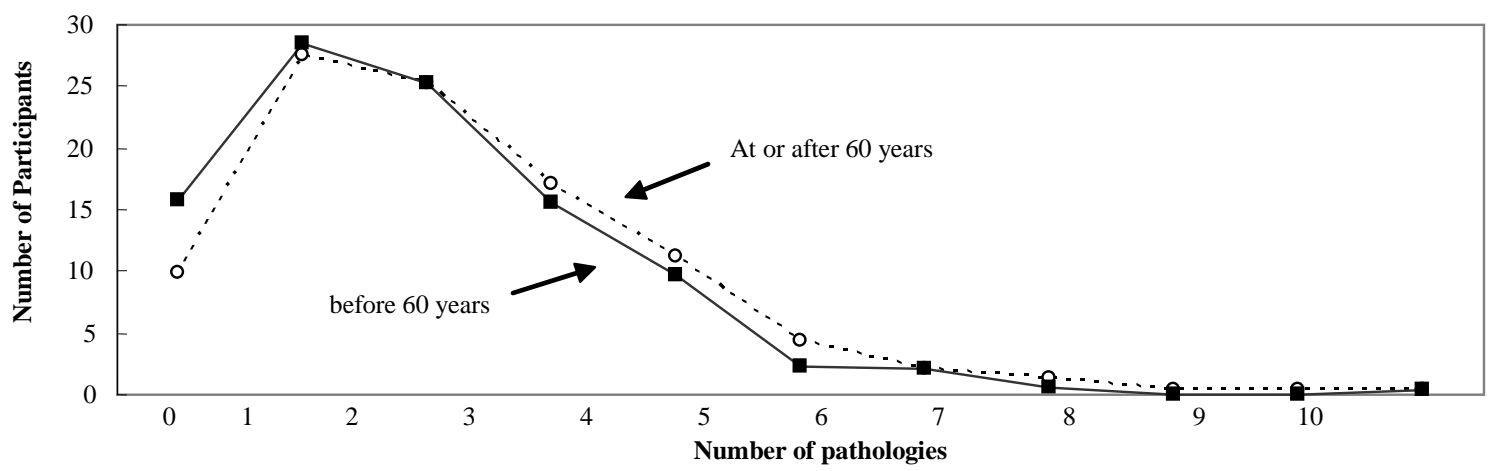

Figure 2.

Number of pathologies experienced by each group of participants since retiring.

Table 3.

Results of the factorial analysis

\begin{tabular}{ccc}
\hline & $\begin{array}{c}\text { Factor 1 } \\
\text { (a) Relationship between } \\
\text { former occupation and } \\
\text { adaptation to retirement }\end{array}$ & $\begin{array}{c}\text { Factor 2 } \\
\text { (b) Effect of physical } \\
\text { capacities on adaptation } \\
\text { to retirement }\end{array}$ \\
\hline Well-being & 0.585 & -0.572 \\
$\begin{array}{c}\text { Satisfaction } \\
\text { with life }\end{array}$ & $0.784^{*}$ & -0.112 \\
Boredom & $-0.774^{*}$ & 0.022 \\
$\begin{array}{c}\text { Number of } \\
\text { pathologies }\end{array}$ & -0.008 & $0.946^{*}$ \\
$\begin{array}{c}\text { Explained } \\
\text { variance } \\
\text { Total } \\
\text { variation }\end{array}$ & 1.558 & 1.236 \\
\hline
\end{tabular}

Note: ${ }^{*}>0.70$.

produce the best predictive model based on the selected variables.

The selected criteria concern the item: "Are you satisfied with the age you were when you retired?” The predictors were: 1) the variables correlated with each of the two factors of adaptation (satisfaction with life, boredom and number of pathologies); and 2) the socio-demographic characteristics of the participants (sex, family situation, academic level and place of residence) (see Tables 4 and 5).

For both groups, the main predictor of satisfaction with age at retirement was academic level. The other significant predicttors were 1) boredom, place of residence and sex for individuals who retired before $60\left(\mathrm{R}^{2}=0.118\right.$; $\mathrm{F}(4,239)=7.88 ; p<$ 0.0000 ); and 2) sex and the number of pathologies for individuals who retired after 60 years old $\left(\mathrm{R}^{2}=0.111, \mathrm{~F}(3,350)=\right.$ 14.51, $p<0.0000)$.

\section{Discussion}

The aim of this research was to determine whether and how different social profiles and retirement ages affect senior citizens' feeling of well-being and adaptation to retirement. We compared the results of people who retired from professional life before and after the age of 60, using a set of scales measureing adaptation to retirement and satisfaction with the age of retiring.

\section{Table 4.}

Results of the forward stepwise regression analysis (individuals who retired before 60 years).

\begin{tabular}{|c|c|c|c|c|}
\hline \multirow{3}{*}{ Predictors } & \multicolumn{4}{|c|}{ Retirement before 60 years } \\
\hline & \multicolumn{4}{|c|}{$\begin{array}{l}\text { Are you satisfied with the age you were } \\
\text { when you retired? }\end{array}$} \\
\hline & Beta & $\mathrm{R}^{2}$ & F & $\mathrm{p}$ \\
\hline \multicolumn{5}{|l|}{1} \\
\hline Academic level & 0.25 & 0.06 & 16.04 & 0.000 \\
\hline \multicolumn{5}{|l|}{2} \\
\hline Academic level & 0.27 & 0.09 & 12.10 & 0.000 \\
\hline Boredom & 0.17 & & & \\
\hline \multicolumn{5}{|l|}{3} \\
\hline Academic level & 0.28 & 0.10 & 9.43 & 0.000 \\
\hline Boredom & 0.16 & & & \\
\hline Place of residence & 0.12 & & & \\
\hline \multicolumn{5}{|l|}{4} \\
\hline Academic level & 0.27 & 0.11 & 7.88 & 0.000 \\
\hline Boredom & 0.17 & & & \\
\hline Place of residence & 0.12 & & & \\
\hline Gender & -0.11 & & & \\
\hline
\end{tabular}

Table 5.

Results of the forward stepwise regression analysis (individuals who retired at or after 60).

\begin{tabular}{ccccc}
\hline \multicolumn{5}{c}{ Retirement at or after 60 years } \\
\hline Predictors & \multicolumn{4}{c}{ Are you satisfied with the age you were } \\
& Beta & $\mathrm{R}^{2}$ & $\mathrm{~F}$ & $\mathrm{p}$ \\
\hline Step 1 & & & & \\
Academic level & 0.20 & 0.04 & 15.09 & 0.000 \\
Step 2 & & & & \\
Academic level & 0.18 & 0.05 & 8.96 & 0.000 \\
Gender & -0.09 & & & \\
Step 3 & & 0.05 & 6.64 & 0.000 \\
Academic level & 0.18 & & & \\
Gender & -0.09 & & & \\
Number of pathologies & 0.07 & & &
\end{tabular}


Overall, our sample appeared to have adapted well to retirement and showed a true sense of satisfaction with their retired life. Nevertheless, different profiles of satisfaction and wellbeing emerged when different variables were isolated in each group, providing a clearer picture of the mechanisms of satisfaction with retirement. For example, appreciation of the age of retiring varied between the two groups. Those who retired after the age of 60 spoke positively of their age when they left work, whereas those who retired earlier expressed regrets about their age. Those who retired after the age of 60 considered that the age at which they retired was satisfactory and a normal time of life to stop working. By contrast, those who retired before 60 thought that they had retired too early and would have preferred to stop work later. With no information about why the participants had retired at a particular age, the difference of appreciation observed in each group remains purely descriptive. However, the literature reports that the reasons motivating an individual to retire from professional life have a major impact on the way this transition is experienced. Research has shown that involuntary retirement can have a negative impact on adaptation (Bossé, Spiro, \& Levenson, 1997), individuals who retire involuntarily tending to be more anxious, depressed or stressed than those who retire voluntarily (Sharpley \& Layton, 1998).

Analysis of the quality of adaptation to retirement according to retiring age using questionnaires of well-being (Diener, Such, Lucas, \& Smith, 1999), satisfaction with life (Ryff \& Keyes, 1995), and boredom (Gana \& Akremi, 1998), and a list of pathologies to which elderly people are potentially at risk (adaptation-OARS; Duke University, 1978), reveal different profiles of adaptation depending on whether the retiring age is before or after the age of 60 .

Our sample as a whole had adapted well to this period of transition, with scores indicating a state of well-being and satisfaction with retired life and low scores for boredom and ill-health.

Regarding the evaluation of well-being, people who retired after the age of 60 considered their health to be better than that of their peers. It thus seems that extending working life contributes to satisfactory health, and that prolonged contact with the professional and social environment of work to an advanced age favours good health among the retired population. Many studies refer to the importance of the social environment and its effects on health (Unger, McAvay, Bruce, Berkman, \& Seeman, 1999) and well-being (Sarason et al., 1990; Vaux, 1990; Prince, Harwook, Blizard, Thomas, \& Mann, 1997).

Our results show that people who retire before the age of 60 years, and particularly those who are married, seem more satisfied with their life than other retirees. The possibility of sharing more time with the spouse remains a criterion of satisfaction for people who retire early. According to Atchley (1976), recently retired people go through a euphoric phase in which they aim to achieve things they had never had time to do. Gilford (1984) makes similar observations: newly retired couples tend to compensate for the decrease in professional activities by spending more time together, thus intensifying the couple's interdependence. We also observed that the retiring age had significant effects on the feeling of boredom and on the evaluation of health.

Two important elements emerged:

1) Participants who retired before the age of 60 express more boredom than those who retired later.

2) The number of pathologies reported by people who retired early is greater than those reported by people who retired after 60.

In line with Parkes' conclusions (1971) concerning various life transitions, we observed that when a change takes place gradually (as is the case for people who retire after the age of 60 ), the person has more time to prepare for the new lifestyle; the probability for the retired person to be satisfied with this change is greater than if retirement is seen as being early.

Finally, with regard to the factors of satisfaction with retiring age, the variables extracted from our analyses appear to be reliable indicators of satisfaction for both groups; for the early retired population, the final model explained $10 \%$ of the variance. However, for people who retired after 60, the model explained only $5 \%$ of the variance. The main factors of satisfaction with retiring age are identical in the two groups. In princeple, and irrespective of the participants' age, a high level of education appears to be the main factor of satisfaction with the time of retiring; a high academic qualification leading to good living conditions produces a feeling of satisfaction with retirement.

In short, the main finding of our study highlights the importance of drawing attention to the retiring age, which emerged as a significant factor in successful transition to retirement. While the conditions for retiring are largely determined by law, only the individual can determine his/her own readiness for retirement based on self-image and perception of his/her capacities. Our study reveals that socio-economic variables have a limited predictive impact on how well people adapt to retirement. In line with the work of Floyd et al. (1992) on life satisfaction, our study reveals that the way individuals see themselves in their own life and their perception of retirement largely determines their satisfaction with the age at which they stop work. Sociodemographic factors are of secondary importance. Similar results have been reported by Ryff, 1995. Life experiences and how they are interpreted are the clue to overall life satisfaction.

Like all research, this study has its limitations. The first is psycho-sociological. Our sample consisted of retirees belonging to the upper social classes, who were well-educated, in good health, and had mostly adapted well to retirement. This sample is thus not representative of the retired community as a whole, but it reveals the existence of a link between boredom and regret at retiring too early, generally before the age of 60 . The second limitation concerns the lack of information about how our participants had prepared their retirement. Many studies insist on the need to prepare workers for retirement from the professional world. Research has shown that preparation for retirement is often associated with better adaptation and with a low level of psychological distress (Lo \& Brown, 1999; Sharpley \& Layton, 1998). A period of preparation would allow the future retiree to develop a favourable attitude towards retirement, to have a better understanding of his means, and to be less nostalgic of his previous professional life.

\section{REFERENCES}

Atchley, R. C. (1976). The sociology of retirement. Cambridge: Schenkman.

Bosse, R., Aldwin, C. M., Levenson, M. R., \& Workman-Daniels, K. (1990). Differences in social support among retires and workers: Findings from the normative aging study. Psychology and Aging, 5, 41-47. doi:10.1037/0882-7974.5.1.41

Bossé, R., Spiro, A., \& Levenson, M. R. (1997). Retirement as a stress- 
ful life event. In T. W. Miller (Ed.), Clinical disorders and stressful life events (pp. 325-350). Madison: International Universities Press.

Calasanti, T. M. (1996). Gender and life satisfaction in retirement: An assessment of the male model. Journal of Gerontology: Social Sciences, 51, S18-S29.

Diener, E., Suh, E. H., Lucas, R. E., \& Smith, H. L. (1999). Subjective well-being: Three decades of progress. Psychological Bulletin, 125, 276-302. doi:10.1037/0033-2909.125.2.276

Duke University Center for the Study of Aging and Human Development (1978). Multidimensional functional assessment: The OARS methodology. Durham, NC: Duke University.

Elwell, F., \& Maltbie-Crannel, A. D. (1981). The impact of role loss upon coping and life satisfaction of the elderly. Journal of Gerontology, 36, 223-232.

Feldman, D. C. (1994). The decison to retire early: A review and conceptualization. Academy of Management Review, 18, 285-311.

Floyd, F. J., Haynes, S. N., Doll, E. R., Winemiller, D., Lemsky, C., Burgy, T. M., Werle, M., \& Heilman, N. (1992). Assessing retirement satisfaction and perceptions of retirement experiences. Psychology and Aging, 7, 609-621. doi:10.1037/0882-7974.7.4.609

Gana, K., \& Akremi, M. (1998). L'échelle de disposition à l'ennui (EDE): Adaptation française et validation du Boredom proneness scale (BP). L'année Psychologique, 98, 429-450. doi:10.3406/psy.1998.28576

Ginn, J., \& Arber, S. (1996). Gender, age, and attitudes to retirement in mid-life. Ageing and Society, 16, 27-55. doi:10.1017/S0144686X00003123

Gaullier, X. (1997). Emploi et retraite. Du risqué “fin de carrière” à la pluriactivité à tout âge. Lien Social et Politiques RIAC, 38, 63-72.

Gilford, R. (1984). Contrasts in Marital satisfaction throughout old age: An Exchange Theory and analysis. Journal of Gerontology, 39, 325-333.

Henkens, K. (1999). Retirement intentions and spousal support: A multi-actor approach. Journal of Gerontology: Social Sciences, 54b, S63-S73. doi:10.1093/geronb/54B.2.S63

Lo, R., \& Brown, R. (1999). Stress and adaptation: Preparation for successful retirement. Australian and New Zealand Journal of mental Health Nursing, 8, 30-38. doi:10.1046/j.1440-0979.1999.00127.x

Maule, A. J., Cliff, D. R., \& Taylor, R. (1996). Early retirement decisions and how they affect later quality of life. Ageing and Society, 16, 177-204. doi:10.1017/S0144686X00003287
Midanik, L. T., Soghikian, K., Ransom, L. J., \& Tekawa, I. S. (1995). The effect of retirement on mental health and health behaviors: The Kaiser Permanence Retirement Study. Journal of Gerontology Social Sciences, 50B, S59-S61. doi:10.1093/geronb/50B.1.S59

Parkes, C. M. (1971). Psycho-social transitions: A field for study. Social Science and Medicine, 5, 101-115. doi:10.1016/0037-7856(71)90091-6

Prince, M. J., Harwook, R. H., Blizard, R. A., Thomas, A., \& Mann, A H. (1997). Social support deficits loneliness and life events as risk factors for depression in old age: The Gospel Oak Project. Psychological Medecine, 27, 323-332. doi:10.1017/S0033291796004485

Ryff, C. D. (1995). Psychological well-being in adult life. Current Directions in Psychological Science, 4, 99-104. doi:10.1111/1467-8721.ep10772395

Ryff, C. D., \& Keyes, C. L. (1995). The structure of well-being revisited. Journal of personality and Social Psychology, 69, 719-727. doi:10.1037/0022-3514.69.4.719

Sarason, B. R., Pierce, G. R., \& Sarason, I. G. (1990). Social support: The sense of acceptance and role of relationships. New York: Wiley.

Schulz, K. S., Morton, K. R., \& Weckerle, J. R. (1998). The influence of push and pull factors on voluntary and involuntary early retirees' retirement decision and adjustment. Journal of Vocational Behavior, 53, 45-57.

Sharpley, C. D., \& Layton, R. (1998). Effects of age of retirement, reason for retirement and pre-retirement training on psychological and physical health during retirement. Australian Psychologist, 33, 119-124. doi:10.1080/00050069808257392

Stull, D. E. (1988). A dyadic approach to predicting well-being in later life. Research on Aging, 10, 81-101. doi:10.1177/0164027588101004

Unger, J. B., Mc Avay, G., Bruce, M. L., Berkman L., \& Seeman, T. (1999). Variation in the impact of social network characteristics on physical functioning in elderly persons: Mac Arthur studies of successful aging. Journal of Gerontology, 54, 245-251.

Vaux, A. (1990). An ecological approach to understanding and facilitating social support. Journal of Social and Personal Relationships, 7, 507-518. doi:10.1177/0265407590074007

Villani P. J., \& Roberto, K. A. (1997). Retirement decision-making: Gender issues and policy implications. Journal of Women and Aging, 9, 151-163. doi:10.1300/J074v09n01_12 